\title{
Arreda Boi: a brincadeira do Boi- de-mamão como resistência e profanação no processo educativo das culturas populares
}

Sônia Laiz Vernacci Velloso (Esha) ${ }^{1}$

Recebido em: 19/02/2019

Aprovado em: 06/11/2019

DOI: $10.5965 / 2358092521222019009$

${ }^{1}$ Mestra em Teatro pela Universidade do Estado de Santa Catarina (UDESC). Professora no curso de dança da Universidade Regional de Blumenau (FURB). E-mail: eshaprem2015@gmail.com 


\section{RESUMO}

Este artigo propõe-se a olhar para a brincadeira popular do Boi-de-mamão, tradicional no litoral catarinense, do grupo Arreda Boi da localidade da Barra da Lagoa, situada no município de Florianópolis (SC), a partir da minha experiência na condição de artista, arte educadora e brincante participante do grupo, num período onde a arte e a cultura popular estiveram muito próximas das políticas públicas de cultura. Esse olhar visa refletir sobre a permanência da brincadeira na comunidade, analisando os períodos de existência do grupo e traçar alguns questionamentos no que se refere à sustentabilidade, desenvolvimento e transformações na estrutura do grupo, abordando o conceito de brincadeira e jogo num aspecto de resistência frente à pressão das elites para a homogeneização da cultura.

Palavras-chave: cultura popular, brincadeira, profanação, Boi-de-mamão.

\section{ABSTRACT}

This article aims to look at the popular play of the Boi-deMamão, traditional on the coast of Santa Catarina, Brazil, made by Arreda Boi group of Barra da Lagoa, located in Florianópolis (SC), from my experience in the lead as an artist, art educator and joking participant of the group, in a period where popular art and culture were very close to the public politics of culture. This view aims to reflect on the permanence of play in the community, analyzing the periods of existence of the group and draw some questions regarding the sustainability, development and changes in the group structure, addressing the concept of joke and play in an aspect of resistance against to the pressure of the elites for the homogenization of the culture.

Keywords: popular culture, joke, desecration, Boi-de-mamão. 


\section{PASSARINHOS E PARDAIS, NÃO SÃO TODOS IGUAIS}

Já tinha visto o Boi-de-mamão na cidade de Florianópolis, em uma apresentação de rua e no espaço da escola também, mas fui conhecer mesmo a brincadeira no meu encontro com o grupo Arreda Boi. Foi a partir daí que fui compreendendo o funcionamento da brincadeira, a partir da vivência na comunidade, no movimento do fazer, no olhar de brincante ${ }^{2}$.

Cheguei ao Arreda Boi convidada para ensinar o grupo a fazer máscaras. $\mathrm{Nado}^{3}$ estava pensando em novos formatos de figurinos para alguns bichos e eu propus uma oficina com máscaras de papelão e papietagem. O grupo, além dos bonecos tradicionais do Boi-de-mamão, queria inventar personagens mascarados para o Urubu, Macaco e Ursos, personagens que não são bonecos-máscaras ${ }^{4}$.

Nado e eu nos conhecemos no grupo de pesquisa em Teatro em Comunidades (FOFA), da UDESC, e ele me chamou pela minha experiência em confecção de bonecos de pano voltados ao público infantil. Essa habilidade se estendeu às formas animadas de teatro no decorrer da graduação do curso de Teatro da UDESC.

O grupo se reunia aos sábados na escola municipal da comunidade da Barra da Lagoa, a Escola Básica Prefeito Acácio

2 Brincante é o termo usado para se referir aos integrantes de folguedos e manifestações populares da cultura nordestina. São atores, músicos e bailarinos que lidam com a arte como uma "brincadeira". Entre essas pessoas já se utiliza a expressão "brincar", para se referir a participar da manifestação, por isso o termo "brincante" (Seu Martelo, 2016).

3 Reonaldo Manoel Gonçalves, morador da comunidade da Barra da Lagoa, educador popular, pesquisador e coordenador do grupo Arreda Boi de Boi-de-mamão em Florianópolis, doravante chamado de Nado no contexto do Arreda Boi.

4 Terminologia utilizada por Beltrame (2007) para designar um tipo de máscara que encobre todo o corpo, um boneco animado pela ação de um mascaramento corporal. 
Garibaldi São Thiago, no contexto do programa Escola Aberta5. Nessa oficina que ministrei participaram adultos e crianças, havia muitas pessoas e aqueles que tinham mais habilidade ajudavam quem tinha menos. Pouco depois da oficina de máscaras, fui chamada para pensar os figurinos que acompanhavam as máscaras e os bonecos. E assim fui chegando, de mansinho, colaborando naquilo que eu sabia, trocando, participando e me envolvendo. Posso dizer que foi minha experiência em teatro, no fazer teatral que me levou até o Boi.

Como quase todos os grupos de Boi da cidade, boa parte dos participantes é constituída por relações de parentesco e no Arreda não é diferente, o grupo iniciava uma nova fase sob a coordenação de $\mathrm{Nado}^{6}$. O grupo era grande, entre 20 e 30 pessoas, havia muitas crianças e vários adultos, alguns pais participavam junto com os filhos, em sua maioria, alunos da escola. Essa formação contava com a participação de artistas e amigos de fora da comunidade, além dos moradores, antigos participantes.

No que se refere à parte musical, Ronei $^{7}$ cuidava da percussão, levando boa parte das crianças para tocar os tambores, Eva $^{8}$ fazia frente na cantoria, desde os exercícios vocais até os arranjos corais. João ${ }^{9}$ acompanhava na sanfona, Alexandre en-

5 Escola Aberta é um programa governamental que incentiva e apoia a utilização do espaço escolar nos finais de semana, em especial aquelas localizadas em territórios de vulnerabilidade social. A estratégia potencializa a parceria entre escola e comunidade ao ocupar criativamente o espaço escolar aos sábados e/ ou domingos com atividades educativas, culturais, esportivas, de formação inicial para o trabalho e geração de renda oferecidas aos estudantes e à população do entorno.

6 Nado ficou na coordenação do Arreda Boi de 1994 a meados de 2000, quando passou às mãos de Ronei.

7 Ronei Manoel Gonçalves, irmão de Nado, morador da Barra da Lagoa, educador e integrante do Arreda Boi, já foi organizador do grupo anos antes.

8 Evanelise Figueiredo de Oliveira é música, cantora e brincante da cultura popular. Foi integrante do Arreda Boi de 2010 a 2012.

9 João Tragtenberg é sanfoneiro e produtor cultural. Integrou o grupo como ar- 
trava com um violão ou guitarra e Nado regia tudo, chamava as pessoas, organizava os ensaios, administrava o projeto e cuidava das crianças.

Esse grupo se formara a partir do início do projeto do Ponto de Cultura ${ }^{10}$, Nado chamou os artistas para comporem a equipe de oficineiros do Boi-de-mamão, que contava com a experiência dos antigos brincantes como Dona Ivone ${ }^{11}$, Ronei, Elói ${ }^{12}$, Alexandre ${ }^{13}$ e de novos artistas que viriam a colaborar com novas técnicas e práticas, como Eva e João, que também foram convidados a partir do contato pelo FOFA, da UDESC. Através do projeto, todos os colaboradores recebiam uma ajuda de custo para poderem se dedicar ao compromisso dos ensaios e oficinas.

O Arreda Boi é fruto basicamente de dois trabalhos realizados na Barra da Lagoa. O primeiro realizado por Nado, entre 1992/1993 com o Grupo de Idosos Primavera, um trabalho de pesquisa sobre as danças e brincadeiras da infância e da juventude desses idosos, onde o Boi-de-mamão passou a ser brincado. O outro trabalho veio de um projeto de estágio na comuni-

tista e brincante. Ficou no Arreda em 2010 e 2011.

10 Pontos de Cultura eram propostas culturais dentro do Programa Cultura Viva, criado pelo Ministério da Cultura, o MinC em julho de 2004, durante o governo Lula, na gestão de Gilberto Gil, tendo Célio Turino como coordenador do projeto. Constituiu-se em uma política pública de cultura que se entende como uma rede de criação e gestão cultural, com ações e reflexões que buscaram destacar a relação entre cultura e cidadania. O programa surge com a proposta de potencialização de iniciativas e organizações que já existem e que já atuam na área da cultura. Nesse sentido ele propõe uma redefinição da função do Estado como parceria, como gestão compartilhada, dividindo espaços e promovendo novas possibilidades, assumindo os sujeitos sociais como protagonistas das ações culturais.

11 Ivone Cecília Gonçalves, moradora da Barra da Lagoa, rendeira, coordenadora do grupo de idosos Primavera e cantante no coro do Arreda Boi.

12 Elói Pereira, morador da Barra, brincante, artista das Artes Cênicas, antigo integrante e especialista na construção e restauração dos bonecos do Arreda.

13 Alexandre Linhares, morador da comunidade da Barra da Lagoa, músico, educador e integrante do Arreda Boi desde o início. 
dade, supervisionado pela professora Márcia Pompeo Nogueira do curso de Artes Cênicas do CEART, UDESC, com o objetivo de construção e manipulação de bonecos do Boi-de-mamão. Com o fim do projeto de estágio as crianças e adolescentes, que dele participaram, migraram para o trabalho que estava sendo desenvolvido com o Grupo Primavera e em 1994 nascia o grupo de Boi-de-mamão, que passou a ser chamado de Arreda Boi. Em 1997, oficializou-se como pessoa jurídica, passando a ser a Associação Cultural Arreda Boi, estabelecendo como finalidade: "Resgatar, preservar e divulgar as manifestações culturais do município de Florianópolis" (ASSOCIAÇÃO CULTURAL ARREDA BOI, 2014, p.15).

O Arreda atua para reavivar as danças e cantigas populares, para que permaneçam vivas no cotidiano da comunidade da Barra da Lagoa e da cidade de Florianópolis, difundindo e compartilhando essas práticas culturais e artísticas com indivíduos e coletivos de outros contextos, assim como também aprendendo outras práticas, vivenciando e trocando saberes.

Desde o início foram sendo chamados novos e novas artistas para a brincadeira, no sentir da necessidade e da vontade de aperfeiçoamento técnico e artístico, quase todos oriundos do FOFA. No início, Eva veio para dar corpo ao coral de vozes cantantes e passou a ser também a cantadora, trazendo junto seus pais para engrossar o caldo das vozes; João chegou contribuindo como um sanfoneiro jovem, mas com experiências diversificadas; Paulo de Tarso, companheiro de Eva, também adentrou ao universo popular como violonista. Eu, quando cheguei, atuei como figurinista, propondo uma nova cara aos aspectos do vestuário do grupo e dos bichos também.

Essa relação entre técnica, prática comunitária e novos artistas foi concedendo ao grupo uma segurança no fazer artístico que abriu muitos espaços de apresentação. Se por um lado o grupo parecia aprender outras maneiras de se colocar em cena, de acreditar na qualidade do trabalho, nós, os artistas "de fora" também aprendemos um novo jeito de ver e fazer arte, com mais simplicidade, menos ansiedade no produto final, mais respeito aos processos individuais dentro do coletivo. 


\section{QUEM QUER FESTA, SUA-LHE A TESTA}

Em 2012, o Arreda Boi foi contemplado no Edital de Apoio às Culturas do Fundo Municipal de Cultura de Florianópolis ${ }^{14} \mathrm{com}$ o Projeto Escola de Boi-de-mamão: prática pedagógica da brincadeira do Boi-de-mamão. Esse projeto englobava três ações: uma prática de revisitação do Boi-de-mamão na comunidade de Ratones; uma mostra de processo e construção de bonecos de Boide-mamão baseada na obra de Franklin Cascaes $^{15}$ no Museu de Antropologia e Etnologia Professor Oswaldo Rodrigues Cabral, MArquE, da Universidade Federal de Santa Catarina; e oficinas para funcionários/as da Rede Pública de Ensino de Florianópolis.

Esse projeto foi um importante exemplo sobre as especificidades que um grupo, que trabalha com a chamada Cultura Popular, enfrenta em meio às práticas de produção comuns da arte mais convencional ou comercial. A tentativa de trabalhar nesses moldes, convidando uma produtora para ajudar a administrar o projeto, acarretou mal-entendidos e desacordos com relação aos recursos do projeto, que eram escassos para tantas ações, assim como em relação aos valores pagos a cada artista.

Os recursos que eram destinados como ajuda de custo aos integrantes do grupo em suas diversas funções, seja como oficineiros, artesãos ou brincantes, num certo momento foram postos em cheque, na medida em que os artistas que se integraram ao grupo cobraram seu valor como artistas profissionais e não apenas como brincantes, tornando bastante diverso o valor destinado a cada integrante.

14 Em 2012 a Prefeitura Municipal de Florianópolis, por meio da Fundação Cultural de Florianópolis Franklin Cascaes (FCFFC), em associação com o ConseIho Municipal de Política Cultural de Florianópolis (CMPCF) disponibilizou para o Fundo Municipal de Cultura de Florianópolis (FMCF) o montante de R\$1,15 milhão em recursos próprios. O apoio financeiro viabilizou a realização de 73 projetos culturais em 10 (dez) setores artísticos e culturais.

15 Franklin Cascaes foi um importante artista catarinense, pesquisador, ambientalista e folclorista, que dedicou parte de sua vida ao registro das tradições, lendas, usos e costumes dos moradores da Ilha de Santa Catarina. Nascido em 1908 e falecido em 1983. O acervo deixado pelo artista encontra-se hoje no MArquE. 
Essa distinção acabou por criar um descontentamento e uma desconfiança por parte de alguns, pois até então os recursos eram divididos igualmente, independentemente do tamanho do trabalho realizado, como forma de economia solidária. Por outro lado, começou a verificar-se que havia uma diferença grande também em relação ao tempo dedicado à execução do projeto, gerando desgaste para aqueles que estavam na produção, o que também exigia maior valorização desse trabalho.

A meu ver, essa experiência nos ensinou alguns entendimentos. Um deles é que participar de uma brincadeira popular requer uma lógica própria, comprometida com o fazer comunitário, com o prazer de estar junto, que parte de um princípio igualitário de valor e de organização. A presença da figura da produtora no grupo, comum nas produções artísticas convencionais, distanciou o grupo da organização de seu fazer, que não era o de "profissionais" fazendo seu trabalho, mas de amigos que se reúnem para brincar, eventualmente com algum recurso financeiro para que possam se dedicar ao grupo sem prejuízo das horas de trabalho do seu ganha-pão.

O padrão "profissional" que foi tomando o grupo, ao mesmo tempo em que garantia mais visibilidade ao Arreda e, com isso, mais convites para apresentações e projetos, valorizando o grupo no "mercado de Bois" da cidade, também perdia algo inerente à brincadeira tradicional, que era, justamente, criar um espaço-tempo de não-trabalho, de criação e reflexão livres, de relaxamento e descanso das obrigações cotidianas.

O sentido do trabalho, no contexto contemporâneo, corresponde ao trabalho produtivo na obtenção e circulação de capital, e o lazer desse mesmo contexto também vem a ser uma ocupação de entretenimento, o que seria diferente da ideia de tempo livre. Esse tempo, por estar ocupado com conteúdos "impostos" por uma mídia hegemônica, deixa de ser livre. E é o tempo livre, o ócio, que proporciona um espaço livre, de criação e brincadeira. Por outro lado, vale a reflexão sobre as formas de sobrevivência das brincadeiras populares nesse contexto, a partir de auxílio financeiro de políticas culturais, que exigem um trabalho de produção dos projetos a serem executados. 
Era principalmente nos ensaios que o Arreda brincava. Mais do que ensaiar, os encontros do Arreda Boi proporcionavam grande alegria àqueles que se encontravam. Aos poucos eu aprendia uma nova maneira de brincar, pois Boi-de-mamão é uma brincadeira que também possui suas próprias regras. Aprendia então as regras e arriscava, ao fim dos ensaios, os passos da brincadeira.

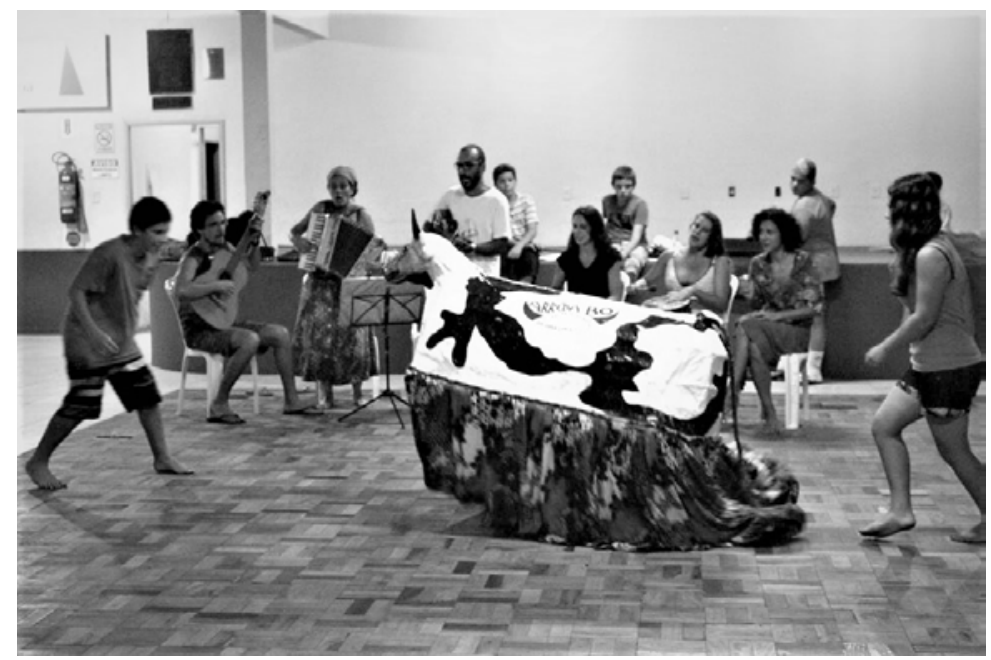

Figura 1: Ensaio regular do grupo Arreda Boi no Conselho Comunitário da Barra da Lagoa.

Fonte: arquivo do grupo (2013).

Cada personagem do Boi tem um passo de dança, de movimento, uma relação própria com os outros personagens. A brincadeira que tem suas regras é também um jogo: Nado sempre nos lembrava para que o jogo acontecesse: quando o Boi entra no terreiro ele quer ver Mateus, mas o Mateus não pode ser visto (ele está sempre atrás do Boi), então o Boi ataca o Vaqueiro, para que o Mateus interceda e ele possa ver o Mateus.

O brincar é uma forma de expressão e de constituição humana que não abarca apenas a infância. Nesse sentido, Moreira 
(2015) argumenta que o brincar é uma necessidade ontológica que se estende ao longo de toda a nossa trajetória. O filme Tarja Branca, de Cacau Rhoden (2014), trata as manifestações populares como um tipo de brinquedo que o adulto pode continuar brincando. Os brincantes seriam adultos que não deixaram de ser crianças, continuam exercitando seu universo lúdico e simbólico, deixando aberto esse espaço de liberdade.

As pesquisas feitas por Reonaldo Gonçalves (2000) sobre Boi-de-mamão na cidade, revelam que a brincadeira, antigamente, era feita exclusivamente por adultos. Contraditoriamente, o jogo do Boi foi se perdendo em sua entrada na escola, que passou a se verificar mais na forma de uma espécie de desfile de personagens. Seo Zé Benta, o mestre do Arreda Boi dizia que:

Antigamente o boi era só de gente adulta, não tinha criança, as crianças ficavam de lado. Naquele tempo quase as crianças não saíam, os pais não deixavam. Enquanto a criança não tivesse 16, 18 anos criasse bigodinho (BENTA apud GONÇALVES, 2000, p. 95).

Colocar a brincadeira como característica de jogo pode nos revelar possibilidades de compreensão da existência da necessidade humana do brincar, do lúdico. Para Huizinga (1990), o jogo revela um paradoxo: estaria na suspensão temporária da vida cotidiana, como uma atividade com finalidade autônoma, mas a sua própria realização, porém, é parte integrante da vida comum. Antônio Nóbrega (2014), no filme de Rohden, afirma: "Eu acho que o brincar é o modo que a gente tem de organizar o nosso mundo, criando um mundo paralelo ao mundo que a gente vive mergulhado cotidianamente".

Para o autor, a limitação também seria uma característica que o jogo impõe como prerrogativa, ele é jogado dentro de limites temporais e espaciais. Quanto à limitação de tempo, ele seria sempre uma nova criação que se conserva na memória e torna-se tradição ao ser transmitido, estabelecendo uma capacidade de repetição. Espacialmente, o jogo, como a brincadeira popular, também delimita, como um "lugar sagrado", o terreno de jogo, onde as regras serão respeitadas. 
Jogar, brincar, na sociedade contemporânea é uma maneira de expressar uma inconformação com o mundo do trabalho, com a incessante atividade de produzir. O fato é que o jogo, para o autor de Homo Luddens (1990), é uma atividade desinteressada, mas culturalmente útil: "em sua qualidade de atividade sagrada, o jogo naturalmente contribui para a prosperidade do grupo social, mas de outro modo e através de meios totalmente diferentes da aquisição de elementos de subsistência" (HUIZINGA, 1990, p. 12). Brincar pode significar uma maneira de impor resistência ao sistema social de acumulação e consumo, colocando-se à parte, como uma espécie de disfarce.

Nesse sentido, Huizinga (1990) atenta para o fato de que, frequentemente, os jogadores acabam por tornarem-se permanentes, criando, nessa constância de encontros, uma comunidade de jogadores. E aqui podemos comparar com os brincantes que criam por meio de um contínuo brincar, um grupo que se reúne continuamente para brincar a mesma brincadeira ou criar novas brincadeiras com novas regras de jogo, rodeadas de mistérios, compartilhadas entre eles.

Para Agambem (2007, p. 60), “o jogo como órgão de profanação, está em decadência em todo o lugar". A profanação aqui se coloca como um conceito importante para esse autor, pois se refere à possibilidade de romper com a perspectiva totalizante do capitalismo, como "religião moderna". O sentido de profanar, para Agambem, tem como contraponto a ideia de sacralizar. Se esta designa a saída das coisas da esfera humana, profanar significa "restituí-las ao livre uso dos homens" (p. 58). Vale dizer que, para Agambem, na fase do capitalismo em que nos encontramos, "espetáculo e consumo são as duas faces de uma única impossibilidade de usar" (p. 64). Nesse sentido, o que não é profanado no capitalismo é entregue ao consumo e à espetacularização.

O jogo, no sentido de Agambem (2007), teria o poder de liberar e desviar a humanidade da esfera do sagrado, sem aboli-lo por completo, um procedimento importante, pois não se processa de forma totalizante. Assim, o sagrado poderia ser devolvido a um uso especial, que não coincidiria com aquele processado pelo consumo utilitarista. 
[...] no jogo. nas danças e nas festas, ele [o homem moderno] procura, de maneira desesperada e obstinada, precisamente o contrário do que ali poderia encontrar: a possibilidade de voltar à festa perdida, um retorno ao sagrado e aos seus ritos, mesmo que fosse na forma das insossas cerimônias da nova religião espetacular ou de uma aula de tango em um salão do interior. Nesse sentido, os jogos televisivos de massa fazem parte de uma nova liturgia, e secularizam uma intenção inconscientemente religiosa. Fazer com que o jogo volte à sua vocação puramente profana é uma tarefa política (2007, p. 60).

A transformação da brincadeira em forma de apresentação, espetáculo, como vemos acontecer hoje, reside na separação que o capitalismo faz de toda atividade humana. Para Agambem (2007, p. 71), "uma profanação absoluta e sem resíduos coincide com uma consagração igualmente vazia e integral". Tudo o que é produzido acaba sendo dividido e deslocado a uma esfera onde o uso se torna impossível. A brincadeira que seria para o uso comum, passa a ser objeto de consumo, ou exibição espetacular.

O termo brincadeira, utilizado neste trabalho, procura chamar atenção para a ideia de resistência, em diversos sentidos. Primeiramente porque parte, intrinsecamente, da criação de um espaço-tempo não produtivo ${ }^{16}$. Além disso, por resistir à perspectiva utilitarista, pressupondo uma finalidade não utilitária, que resiste à submissão à esfera do consumo. Por fim, sua capacidade de recriar usos de formas, objetos e mesmo relações sociais.

José Jorge de Carvalho (2010), em uma perspectiva mais otimista do que aquela proposta por Agambem no texto citado acima, acredita que a América Latina tem sido capaz de resistir

160 psicanalista Ricardo Goldenberg observa que “o brincar passou a ser situado como uma atividade ociosa, e, portanto, não séria e infantilizada. Já o mundo dos negócios (negação do ócio) seria uma espécie de emblema dos sujeitos engajados, seriamente, na atual dinâmica do trabalho" (Depoimento em vídeo. In: RHODEN, C. Tarja branca: a revolução que faltava (Documentário). Produção: Estela Renner, Luana Lobo, Marcos Nisti. Roteiro: Cacau Rhoden, Estela Renner, Marcos Nisti. São Paulo: Maria Farinha Filmes, 2014. (80min), son., color. 
à pressão das elites para a homogeneização da cultura. Em relação ao embate com o Estado, que procurou dirigir e controlar os valores simbólicos e estéticos, Carvalho indica que os artistas populares procuraram negociar posições, a fim de manter seus modos e fazeres próprios, por meio de estratégias organizativas mais e menos institucionais. Ele avalia que atualmente, a indústria do entretenimento, braço das classes dominantes apoiada pelo Estado, passou a se interessar pelas manifestações culturais populares visando um interesse comerciável, pelo teor de exotismo, sob os holofotes do entretenimento, para gerar dividendos aos produtores e empresários e à classe média urbana consumidora de espetáculos. E assim, grande parte da cultura popular passou a ser espetacularizada:

Defino "espetacularização" como a operação típica da sociedade de massas, em que um evento, em geral de caráter ritual ou artístico, criado para atender a uma necessidade expressiva específica de um grupo e preservado e transmitido através de um circuito próprio, é transformado em espetáculo para consumo de outro grupo, desvinculado da comunidade de origem [...] (CARVALHO, 2010, p. 47).

Carvalho (2010), se refere a um processo que, em linhas gerais, aponta para a forma de apropriação a que estão sujeitas muitas das tradições populares, A espetacularização desloca a brincadeira de seu lugar de compartilhamento de olhares em um ambiente familiar, comunitário e aberto a trocas, para um lugar de consumo, retirando-lhe o uso comunitário e seu horizonte existencial. Para o autor, a espetacularização ou a canibalização é uma forma predatória que descaracteriza as formas populares gerando a perda de sua autonomia estética e simbólica, para ceder aos interesses da classe dominante.

A experiência sobre a qual procuro refletir, no caso do Arreda, aponta para a complexidade dos processos de espetacularização da cultura popular. Em certa medida, ele aponta também para as contradições e tensões que permanecem no processo. Se, por um lado, as relações de profissionalização e a entrada na escola apontam para o enfraquecimento do potencial de jogo e 
da brincadeira, por outro, a consciência do processo estabelecia alguns parâmetros. Por exemplo, não abrir mão do jogo do Boi com o Vaqueiro tensionava, no sentido de manter certo risco (o que foi perdido com os Bois nas escolas), ou ainda a ridicularização e sátira política durante a morte do Boi, o que havia desaparecido em muitos bois. Essas medidas salvaguardavam a estrutura da brincadeira, mesmo tendo que negociar questões como a restrição de tempo, por exemplo.

\section{POR MORRER UMA ANDORINHA, NÃO ACA- BA A PRIMAVERA}

Com o fim do trabalho de teatro do Oprimido no Arreda, as crianças ficaram com muita vontade de continuar fazendo teatro e eu então fui convidada a dar oficinas de Teatro. Nado começou a pensar em desenvolver novas maneiras de realizar a parte da morte do Boi no Arreda. Existia, claro, um jeito tradicional de fazer, mas cada Boi fazia à sua maneira. Para aproveitar a experiência teatral dos integrantes do grupo e a vontade de atuar da meninada, pensamos em aproveitar as aulas de teatro para desenvolver as cenas do Boi-de-mamão. Essas cenas depois eram testadas e adaptadas nos ensaios do Boi-de-mamão propriamente dito, buscando também combinações musicais com a cantoria.

A apreensão da brincadeira feita pelos aprendizes é o que Barba chama de "técnica codificada de longa duração" (BARBA apud BELTRAME, 2007, p. 163), em que o ator vai constituindo uma preparação corporal psicofísica, incorporando um acervo de procedimentos do mestre do ofício. Valmor Beltrame (2007), relaciona os estudos de treinamento do ator de Eugênio Barba com a técnica de apreensão, animação e interpretação dos atores-dançarinos do Boi-de-mamão, que podem ser identificadas no ato da representação ou mesmo em outros momentos da preparação do "espetáculo". Ao mesmo tempo não constituem um código de normas claramente estabelecido, que o aprendiz antecipadamente deve respeitar. Conforme Beltrame (2007), 
ao aprender observando o modo como outros integrantes do grupo atuam, ou com o "ensaiador", o aprendiz vai assimilando esses procedimentos, compreendendo que a realização da brincadeira exige a incorporação dessa forma de fazer realizada por seus integrantes.

A figura do ensaiador, no nosso caso, era o Nado. Ele trazia todos os aspectos dos modos de fazer a brincadeira, sempre contando uma história dos porquês de serem daquela forma. Ele mostrava como cada personagem tinha seu próprio passo de dança, sua postura e sua localização no jogo e lembrava de alguma história de algum brincante de Boi na cidade.

No início do novo ano, em 2013, a composição do grupo e sua estrutura haviam se modificado. Elói, Ronei, Alexandre, Eva, Paulo, Cleuza e Gilberto se afastaram do grupo após o projeto do Fundo Municipal. João mudou-se para a cidade de Recife, no estado de Pernambuco. Os encontros já não ocorriam mais na escola, visto que a nova diretoria não se interessou na partilha do espaço educativo. A sede dos encontros do Arreda passou a ser o Conselho Comunitário da Barra da Lagoa. Lá nos dividimos em dias de ensaio da cantoria, de percussão, do teatro e da dança do Boi.

As crianças ${ }^{17}$ cresceram e algumas perderam o interesse, mas o grupo de adolescentes que ficou era suficiente para tocar o Boi. E as aulas de teatro incentivavam a participação no Boi, preparava os corpos e a presença para a brincadeira. O trabaIho de teatro no Arreda trouxe uma nova forma de preparação dentro do "treinamento" da brincadeira popular. Alguns adolescentes viam no teatro uma possibilidade de quebrar com inseguranças e com excessiva timidez. Foi uma troca, uma mistura de linguagens que nos caracterizou enquanto grupo.

17 As crianças e adolescentes que participaram do Boi naquele período foram: Amanda Gonçalves, Ananda Gonçalves, Joana Gonçalves, Sávio Cláudio Vieira, Felipe Staroski dos Santos, Ian Staroski dos Santos, Ruan Nascimento Correa, Carlinhos Silva, Karolina S. Gonçalves, lanô dos Anjos Hak, André Domingos Martins (Juca), Adriele Azambuja, lago Angelo Santos, Eduardo Gonçalves Azambuja, Robson. 
Além de o teatro servir como instrumento terapêutico, nesse caso, pude ver claramente os efeitos do exercício do teatro no entendimento da prática da brincadeira do Boi, como jogo de cena do brincante. Um exemplo disso ocorreu na viagem do Arreda Boi às cidades de Condado e Recife, em Pernambuco, em 2015, como realização do projeto de intercâmbio ${ }^{18}$ entre o Cavalo Marinho ${ }^{19}$ Estrela Brilhante e o Boi-de-mamão Arreda Boi, dois grupos de brincadeira tradicional que tem a figura do Boi como elemento central.

Nessa viagem estávamos numa configuração de grupo experiente, pois vínhamos da realização de vários projetos desde a formação do Ponto de Cultura. Basicamente os adultos ficaram na área da música e os adolescentes na dança. Com o retorno de Alexandre Linhares ao grupo, Nado resolveu brincar de Vaqueiro, deixando Alexandre como cantador. Amanda como Mateus, se relaciona principalmente com o Vaqueiro, como um par na brincadeira.

Já em Condado, a cidade dos Cavalos Marinhos, fomos apresentar o Boi na rua, em frente ao espaço do Estrela Brilhante, em meio a uma grande festa na comunidade, que se amontoava ao redor do círculo formado. A brincadeira começou com entusiasmo e o público era inserido na brincadeira, com curiosidade pela novidade. Em dado momento da morte do Boi, Nado (Vaqueiro) provoca Amanda (Mateus) insinuando sua irresponsabilidade pela morte do Boi e corre atrás dela e ela, para responder à altura, inesperadamente, pega um cabo de vassoura escondido e volta atrás do Nado, que sai correndo para não apanhar, numa cena tipicamente cômica da palhaçaria. Todos ficaram às gargalhadas.

18 Esse intercâmbio era o objeto do Projeto Fortalecendo Tradições: Intercâmbio entre Cavalo Marinho e Boi-de-mamão (Funcultura - Fundo Pernambucano de Incentivo à Cultura), a convite do seu proponente João Tragtenberg

19 Cavalo Marinho é um folguedo folclórico tradicional da zona da mata setentrional de Pernambuco, Alagoas e agreste da Paraíba. Apesar de ser uma variação do Bumba meu boi, a brincadeira tem características próprias e além do "auto do boi", podem ser vistos diversos personagens fantásticos do interior do estado. 


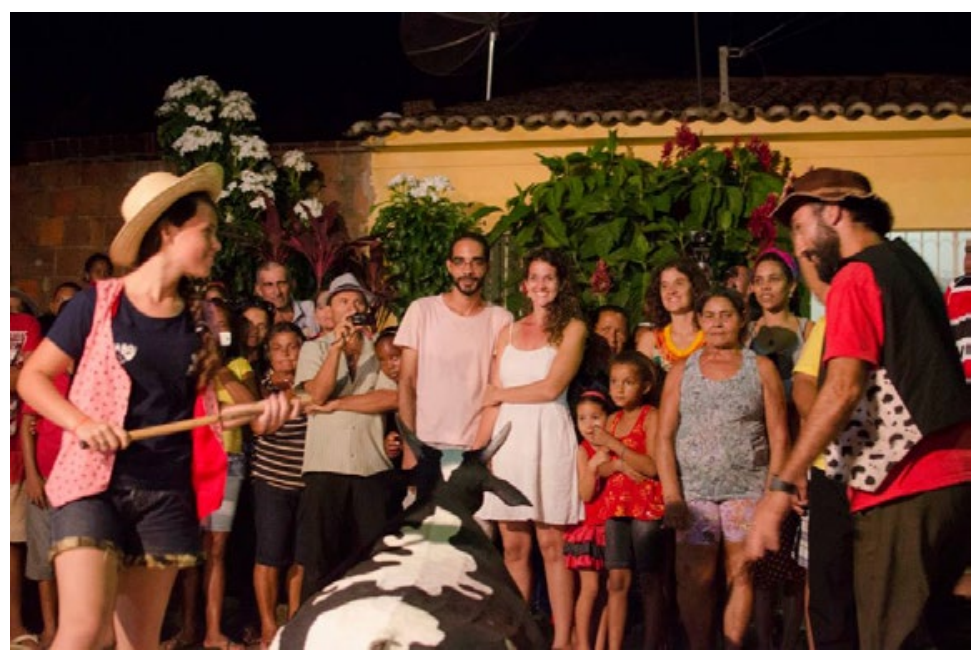

Figura 2: Brincadeira de Boi-de-mamão do Arreda Boi em ocasião do Intercâmbio com o Cavalo Marinho Estrela brilhante em Condado/PE

Foto: Renata Pires (2015).

Esse jogo narrado, no meu entendimento, mostra a dimensão do aprendizado teatral que a adolescente captou nos anos de teatro no Arreda e como isso foi absorvido na dinâmica da brincadeira, revelando que o teatro e a brincadeira popular possuem códigos comuns que podem ser aproveitados mutualmente, sem que percam suas características e regras próprias.

Pensar nas dimensões que uma brincadeira popular pode abranger é pensar em um mundo de possibilidades que pode se abrir para os que brincam e para os que a veem, pois se brincar é uma condição humana, retomar o sentido do brincar seria primeiramente se colocar numa reconexão com essa condição, se humanizar, tornar-se inteiro. Em segundo lugar, brincar como adulto é quebrar paradigmas sociais de dominação na medida em que um sistema sério exige que se trabalhe até mesmo nos momentos de lazer. Em última instância brincar pode ser uma posição política, ou, pelo menos uma atuação política de resis- 
tência às formas hegemônicas que não querem ver sujeitos donos de seu tempo.

Retomando as memórias e reflexões nessa narrativa, reconheço o período de trabalho do Arreda Boi, que iniciou com o projeto do Ponto de Cultura ${ }^{20}$ em 2010 e encerrou-se em 2015 com o projeto do Intercâmbio com o Cavalo Marinho, como um período que se caracterizou pelo aprendizado do grupo com o aporte das políticas públicas de cultura, da influência do teatro como metodologia de trabalho na cena e pela exigência de posturas e formatos profissionais no contexto das brincadeiras populares.

O fomento das políticas culturais proporcionou um aparato técnico que permitiu levar o Arreda para muitos outros lugares, divulgando e preservando imagens do seu trabalho, além de oportunizar encontros e apresentações. A qualidade musical também foi beneficiada, auxiliando os músicos a soarem ainda melhor. As viagens, os convites, os ensaios, os novos bonecos, o carreto de transporte destes (importantíssimo), os figurinos, as oficinas, o teatro, enfim, foram tantos itens na construção do grupo nesse período que realmente pode-se ter uma noção da importância do aporte financeiro no desenvolvimento cultural de grupos como esse.

O Teatro aparece para mim, neste momento, como um grande catalisador, que pode inventar infinitas possibilidades para continuar revelando às pessoas o tamanho desse mundo, a capacidade que a união coletiva pode realizar e a liberdade que se pode viver. O teatro levou técnica ao Boi e o Boi trouxe a brincadeira ao teatro. O Boi, como símbolo táurico do mito de Dionísio, abarca a vida de forma intensa, a morte e o renas-

20 Pontos de Cultura eram a principal ação do programa Cultura Viva, concebido como uma rede orgânica de criação e gestão cultural. A implantação do programa prevê um processo contínuo e dinâmico, e seu desenvolvimento é semelhante ao de um organismo vivo, que se articula com atores pré-existentes. Em lugar de determinar (ou impor) ações e condutas locais, o programa estimula a criatividade, potencializando desejos e criando um ambiente propício ao resgate da cidadania pelo reconhecimento da importância da cultura produzida em cada localidade (BRASIL, 2005, p.18) 
cimento, num ciclo infindável que demonstra a eternidade circunscrita além das formas vivas.

Com o fim do Intercâmbio, Rodrigo Benza e Camila Gastelumendi, voltaram, com seu bebê Joaquim, ao seu país de origem, o Peru, para uma nova fase de vida e trabalho. Os e as adolescentes cansaram da brincadeira, estavam agora mais interessados nas baladas e nas redes sociais para estarem com pessoas da idade deles. E uma estranha doença que acometeu Nado durante os meses subsequentes, marcaram o fim deste período da história.

O Boi morreu. Aproveitamos o luto para rever projetos pessoais que ficaram guardados durante o intenso período dos projetos com o Arreda e renovar ideias e vontades relacionadas ao Boi. Esse Boi que sempre morre e torna a viver revela uma necessidade humana de reconhecer a indestrutibilidade da vida (Kerényi, 2002), num constante e eterno recomeçar e findar de coisas como característica própria, sempre nova, sempre.

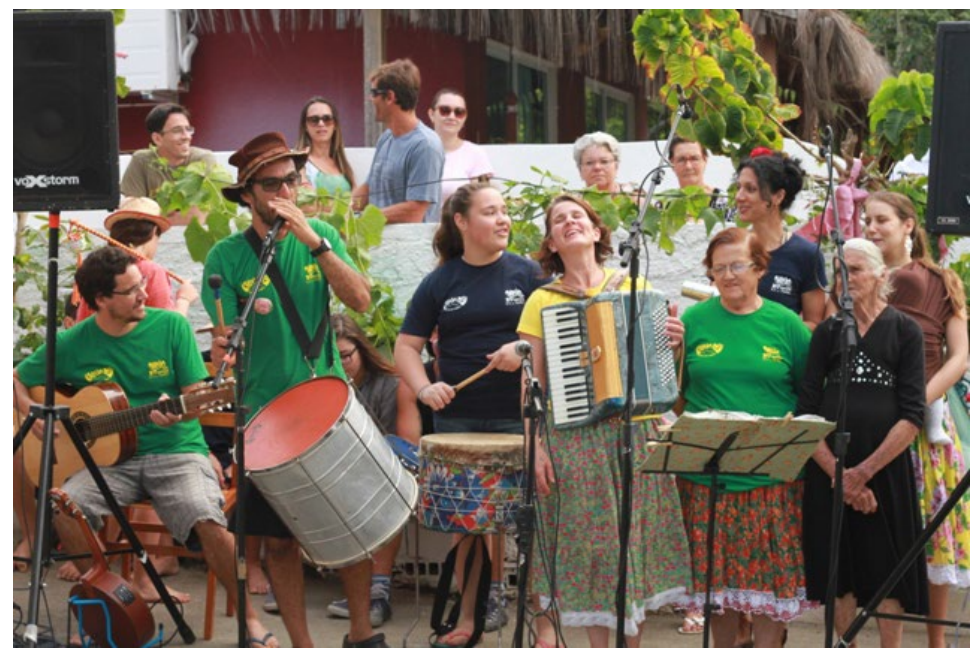

Figura 3: Apresentação do grupo Arreda Boi na casa da Dona Maria do Torquato, na tradicional "Corrida da Bateira" da Barra da Lagoa.

Foto: Renata A. Brito (2014). 


\section{REFERÊNCIAS}

AGAMBEM, Giorgio. Profanações. trad. Selvino José Assman. São Paulo: Boitempo, 2007.

ASSOCIAÇÃO CULTURAL ARREDA BOI. Arreda: É Boi-de-Mamão, vamos brincar!? Associação Cultural Arreda Boi, texto Renata

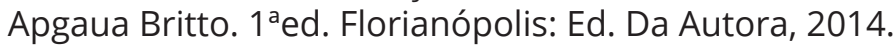

BELTRAME, Valmor. (2007). O ator no boi-de-mamão: reflexões sobre tradição e técnica. Móin-Móin - Revista de Estudos sobre Teatro de Formas Animadas. Jaraguá do Sul SCAR/UDESC, ano $3, n^{\circ} .3$.

CARVALHO, J. Jorge de. 'Espetacularização' e 'canabalização' das culturas populares na América Latina. Revista ANTHROPOLÓGICAS, ano 14, vol.21 (1): 39-76, 2010.

FERREIRA, João Luiz Silva. In.: BRASIL. Cultura Viva: Programa Nacional de Arte, Educação, Cidadania e Economia. Brasília: Secretaria de Programas e Projetos Culturais do Ministério da Cultura, 2005.

FREIRE, Marcelino. Depoimento em vídeo. In.:RHODEN, C. Tarja branca: a revolução que faltava (Documentário). Produção: Estela Renner, Luana Lobo, Marcos Nisti. Roteiro: Cacau Rhoden, Estela Renner, Marcos Nisti. São Paulo: Maria Farinha Filmes, 2014. (80min), son., color.

GONÇALVES, Reonaldo Manoel. Cantadores de Boi-de-mamão: velhos cantadores e educação popular na llha de Santa Catarina. Florianópolis, Dissertação (Mestrado em Educação) - Centro de Ciências da Educação, Universidade Federal de Santa Catarina, 2000.

HUIZINGA, Johan. Homo Ludens: o jogo como elemento da cultura. São Paulo: Perspectiva, 242p. 1990. 
KERÉNYI, Karl. Dioniso: Imagem arquetípica da vida indestrutível. Trad. Ordep Trindade Serra. São Paulo: Odysseus, 2002.

MOREIRA, Andressa Urtiga. Políticas de resistência pelo encantar: o brincar na cultura popular. Psicologia em Estudo, vol. 20, núm. 4, octubre-diciembre, 2015, pp. 687-698 Universidade Estadual de Maringá Maringá, Brasil.

NÓBREGA, Antônio. Depoimento em vídeo. In.:RHODEN, C. Tarja branca: a revolução que faltava (Documentário). Produção: Estela Renner, Luana Lobo, Marcos Nisti. Roteiro: Cacau Rhoden, Estela Renner, Marcos Nisti. São Paulo: Maria Farinha Filmes, 2014. (80min), son., color.

Brincadeiras e apanhados. Ditados populares. 05/03/2009. Disponível em: http://brincarvalho.blogspot.com/2009/03/ ditados-populares.html Acesso em: 18/11/2019. 